\title{
Efeitos da Interação de Potyvirus em Híbridos de Meloeiro, Variedades de Melancia e Abobrinha*
}

\author{
Najara F. Ramos**, J. Albérsio A. Lima*** \& M. Fátima B. Gonçalves \\ Laboratório de Virologia Vegetal, Departamento de Fitotecnia, Universidade Federal do Ceará, Cx. Postal 6046, \\ CEP 60451-970, Fortaleza-CE, Fone: (085) 288-9683, e-mail: albersio@ufc.br
}

(Aceito para publicação em 04/03/2003)

Autor para correspondência: Najara F. Ramos

RAMOS, N.F., LIMA, J.A.A. \& GONÇALVES, M.F.B. Efeitos da interação de potyvirus em híbridos de meloeiro, variedades de melancia e abobrinha. Fitopatologia Brasileira 28:199-203. 2003.

\section{RESUMO}

Em razão da freqüente ocorrência de infecção mista, na natureza, o presente trabalho objetivou estudar o efeito da interação de diferentes espécies de potyvírus em meloeiro (Cucumis melo), melancia (Citrullus lanatus) e abobrinha (Cucurbita pepo). Foram usados os seguintes vírus da família Potyviridae, gênero Potyvirus: Papaya ringspot virus (PRSV); Watermelon mosaic virus, (WMV) e Zucchini yellow mosaic virus, (ZYMV). Os efeitos na sintomatologia das infecções duplas e simples de PRSV, WMV e ZYMV foram avaliados em três híbridos de meloeiro, duas variedades de melancia e abobrinha 'Caserta', em experimentos de casa de vegetação. Os três vírus, isoladamente ou em todas as duplas combinações possíveis, foram inoculados, em plantas dos híbridos de meloeiro Hy Mark, Gold Mine e Orange Flesh, variedades de melancia Crimson Sweet e Charleston Gray e abobrinha 'Caserta', usando-se dez plantas de cada híbrido ou variedade, por combinação de vírus. As inoculações foram efetuadas por meio de extratos de folhas com infecção simples dos respectivos vírus. As plantas inoculadas com cada vírus isoladamente e suas respectivas combinações foram observadas quanto ao aparecimento de sintomas durante 30 dias após as inoculações. Amostras foliares das plantas inoculadas foram, também, testadas por ELISA indireto contra os anti-soros correspondentes para cada vírus. As infecções duplas em meloeiro, melancia e abobrinha revelaram, através da avaliação sintomatológica, que existem interações sinérgicas entre PRSV, WMV e ZYMV. As infecções duplas envolvendo o ZYMV apresentaram alta severidade, exibindo sintomas não encontrados em infecções simples, apesar da severidade nas infecções isoladas do ZYMV.

Palavras-chave adicionais: ZYMV, WMV, PRSV, Potyviridae, sinergismo viral.

\begin{abstract}
Symptoms of potyvirus interactions on melon hybrids, watermelon varieties and zucchini

Considering the frequent natural occurrence of mixed infection of two or more viruses in the same plant, the present research was developed with the objective of studying the symptomatological effects of mixed virus infections in melon (Cucumis melo), watermelon (Citrullus lanatus) and zucchini (Cucurbita pepo). The following virus species from the family Potyviridae genus Potyvirus were used in the study: Papaya ringspot virus (PRSV), Watermelon mosaic virus (WMV), and Zucchini yellow mosaic virus (ZYMV). The symptomatological effects were evaluated in double and single infections in three melon hybrids Hy Mark, Gold Mine and Orange Flesh, two watermelon varieties Crimson Sweet and

Charleston Gray and zucchini 'Caserta'. In greenhouse experiments, PRSV, WMV and ZYMV alone and in all possible double combinations were inoculated in ten-day-old melon, watermelon and zucchini plants, using ten plants of each hybrid or variety per virus combination. Inoculations were performed using leaf extracts from plants infected with each virus. Leaf samples from each virus combination were tested by ELISA against antisera specific for the respective viruses. The symptomatological effects in double virus infections revealed the existence of synergistic interactions between PRSV, WMV and ZYMV in melon, watermelon and zucchini. The double infections involving ZYMV showed severe symptoms and symptoms not present in ZYMV single infection.
\end{abstract}

Cultivadas em praticamente todo o mundo, as espécies da família Cucurbitácea estão distribuídas em aproximadamente 80 gêneros, tendo uma grande importância econômica e social. O Nordeste brasileiro vem se mostrando bastante favorável ao cultivo de diferentes cucurbitáceas,

\footnotetext{
* Parte da dissertação de mestrado do primeiro autor. Universidade Federal do Ceará. (2002)

** Bolsista da FUNCAP

**** Bolsista do CNPq
}

dentre as quais se destacam o meloeiro (Cucumis melo L.) e a melancia [Citrullus lanatus (Thunb) Matsum \& Nakai] dada as condições favoráveis de clima e solo da região. O Nordeste é a região brasileira onde mais se cultiva o meloeiro, sendo que o tipo mais cultivado no Brasil pertence ao grupo inodorus (amarelo) devido à excelente vida útil de pós-colheita, 25 a 30 dias, em condições ambientais (Gonçalves et al, 1996).

A melancia alinha-se entre as cinco mais importantes hortaliças cultivadas no Brasil, sendo o Nordeste brasileiro a 
região mais produtiva (IBGE, 1997). Empresas multinacionais estão lançando no mercado sementes de melancia triplóide, cujos frutos não têm sementes.

A abobrinha (Cucurbita pepo, L.), cv. Caserta, é uma excelente hospedeira para manutenção e multiplicação de vírus, pela sua facilidade de infecção e ótima qualidade de multiplicação dos vírus (Oliveira et al., 2000).

As doenças que mais se destacam sobre meloeiro e melancia e abrobrinha são aquelas ocasionadas por vírus que ocorrem em percentuais elevados, causando prejuízos em produção, em conseqüência das reduções na quantidade e qualidade dos frutos. No Brasil, mais atenção tem sido dada aos vírus da família Potyviridae por representarem fatores limitantes ao cultivo de cucurbitáceas nas principais regiões produtoras do país. O gênero Potyvirus se sobressai em importância econômica para as cucurbitáceas por conter três espécies de relevância para os cultivos do meloeiro e da melancia: vírus da mancha anelar do mamoeiro (Papaya ringspot virus, PRSV); vírus do mosaico da melancia (Watermelon mosaic virus, WMV - antigo WMV-2) e vírus do mosaico amarelo da abobrinha-de-moita (Zucchini yellow mosaic virus, ZYMV). A patologia destas três espécies de vírus e dos potyvírus, de um modo geral, pode ser observada por uma série de sintomas, que incluem mosqueado, mosaico, clorose, necrose, deformação foliar e de frutos e até mesmo infecção latente, sem sintomas macroscópicos (Oliveira et al., 2000).

Os potyvírus podem causar infecções isoladas e mistas, que são observadas com relativa frequiência em condições naturais. Nas infecções mistas podem acontecer relações sinérgicas, causando aumento ou decréscimo na concentração dos vírus na planta, modificação nos sintomas da doença e/ ou alteração na movimentação sistêmica dos vírus (Oliveira et al., 2000).

Em razão da freqüente ocorrência natural de infecção mista entre vírus, a presente pesquisa teve por objetivo estudar os efeitos na sintomatologia de infecções mistas de PRSV, WMV e ZYMV em três híbridos de meloeiro, em duas cultivares de melancia e em abobrinha 'Caserta'.

Isolados de PRSV, WMV e ZYMV usados nas atividades de pesquisa foram obtidos em campos de produção de melão e/ou melancia dos Estados do Ceará (PRSV), Rio Grande do Norte (ZYMV), Bahia e Pernambuco (WMV) (Oliveira et al., 2000), e fazem parte do Banco Ativo de Vírus de Culturas Tropicais do Laboratório de Virologia Vegetal da Universidade Federal do Ceará (UFC).

Experimentos foram conduzidos em casa de vegetação com temperatura variando de 26 a $38{ }^{\circ} \mathrm{C}$. Em todos os casos, o plantio foi realizado em vasos de polietileno de $12 \mathrm{~cm}$ de diâmetro, contendo uma mistura previamente autoclavada de terra e esterco na proporção de 2:1. Os três vírus, isoladamente e em todas as duplas combinações possíveis, foram inoculados em três híbridos de meloeiro Hy Mark, Gold Mine e Orange Flesh, duas variedades de melancia Crimson Sweet e Charleston Gray, e abobrinha 'Caserta'.

Sementes de cada híbrido/variedade foram semeadas em 40 vasos, mantendo-se, após o desbaste, duas plantas por vaso. Os vasos foram distribuídos em oito fileiras, perfazendo um total de oito tratamentos, variando-se a ordem de combinação dos vírus. As inoculações foram feitas dez dias depois do plantio, nas folhas cotiledonares, de acordo com os tratamentos: A) ZYMV; B) PRSV; C) WMV; D) ZYMV e WMV; E) PRSV e WMV; F) PRSV e ZYMV e G) plantas não inoculadas (testemunha).

As inoculações foram efetuadas com inóculos preparados através da maceração de tecidos vegetais infetados com a adição de tampão fosfato de potássio $\mathrm{pH} 7,5$, na proporção 1:2. Nos tratamentos constituídos da inoculação de duas espécies de vírus, as inoculações foram efetuadas isoladamente em folhas diferentes, na mesma ocasião.

A evolução dos sintomas nas plantas inoculadas nos diferentes tratamentos foi acompanhada diariamente, comparada, e as características sintomatológicas foram anotadas e fotografadas, quando julgado necessário. A presença dos vírus em plantas com infecção isolada ou mista foi confirmada através do teste de "enzyme linked immunosorent assay" (ELISA) indireto, realizado 25 dias depois das inoculações.

Os testes de ELISA indireto foram realizados conforme o procedimento descrito por Almeida (2001). Poços de placas de ELISA foram cobertos com $100 \mu \mathrm{l}$ dos extratos obtidos de folhas comprovadamente infetadas com o vírus em questão (antígeno homólogo), folhas de plantas sadias usadas como testemunha e as devidas amostras a serem testadas. Os extratos foram preparados em tampão carbonato, $\mathrm{pH} 9,6$, na proporção de 1:10 (p/v). Após incubação, lavagem e secagem da placa, adicionaram-se $100 \mu \mathrm{l}$ do anti-soro correspondente, diluído na proporção de 1:1.000, previamente absorvidos com extrato de tecido sadio. Após nova incubação, lavagem e secagem, adicionaram-se $100 \mu \mathrm{l}$ de imunoglobulina G (IgG) de cabra anti-IgG de coelho conjugada à fosfatase alcalina, diluída na proporção 1:2.000. A presença do conjugado foi revelada pela adição de $100 \mu \mathrm{l}$ de substrato p-nitrofenil fosfato (Sigma N9389) e subseqüente leituras das placas no aparelho Labsystems Multiskan - MS, utilizando-se o comprimento de onda $405 \mathrm{~nm}$. De acordo com o critério adotado para as análises, foram consideradas positivas as médias das leituras que correspondiam ao dobro das médias dos valores de absorbância registrados para os extratos de plantas sadias, usadas como testemunha.

Os sintomas exibidos pelos híbridos de meloeiro, Hy Mark, Gold Mine e Orange Flesh, quando inoculados com PRSV, WMV e ZYMV isoladamente, manifestaram-se de forma típica para cada um dos vírus em questão. O ZYMV mostrou-se mais severo que os outros dois potyvírus, causando mosaico, bolhosidade e deformação foliar, nos três híbridos estudados (Figura 1A, B e C, Tabela 1), enquanto o PRSV e o WMV causaram somente sintoma de mosaico nos mesmos híbridos (Tabela 1). A severidade do ZYMV constatada em infecções simples e dupla já foi mencionada, sendo a doença ocasionada pelo ZYMV considerada uma das viroses mais destrutivas em cucurbitáceas, ocorrendo, tanto nos trópicos, como em regiões temperadas (Provvidenti et al., 1984; 
Efeitos da interação de Potyvirus em híbridos de meloeiro...

Oliveira et al., 2000). Mesmo menos severo quando comparado com o ZYMV, o PRSV pode ser considerado fator limitante na produção de diversas cucurbitáceas, principalmente quando a infecção ocorre no início do ciclo (Bhargava, 1977;c Oliveira et al., 2000). As reações sintomatológicas causadas pelo WMV foram coincidentes com os sintomas descritos por Perring et al. (1992) que consideram mosaico o principal sintoma, não sendo verificada deformação foliar ou bolhosidade. Ao serem inoculados com ZYMV e WMV os híbridos de meloeiro exibiram, desde o inicio da infecção, sintomas mais severos que os das plantas com infecções isoladas, evidenciando interação sinérgica entre os dois vírus em questão (Figura 1, Tabela 1). Os sintomas da infecção dupla manifestaram-se na forma de mosaico intenso, bolhosidade, deformação foliar forte e enação (Figura 1, Tabela 1). O sintoma de enação, que consistiu em afloramento de bordas de folha no meio do limbo foliar, verificado somente nos casos de infecção com dois vírus (Figura 1D, E e F), caracteriza-se como uma reação típica de sinergismo e de extrema severidade. O quadro sintomatológico nos três híbridos evoluiu com o passar dos dias, prejudicando, por completo, o desenvolvimento das plantas. As conseqüências do sinergismo entre vírus, resultando em doença diferente, com sintomas mais severos, já foram relatadas por Calvert \& Ghabrial (1983) e Poolpol \& Inouye (1986) em outras culturas.

Os sintomas exibidos pelos híbridos de meloeiro quando inoculados com PRSV e WMV foram sempre menos severos do que os apresentados pelos híbridos quando inoculados com as combinações de ZYMV + WMV e ZYMV + PRSV (Tabela 1). Estes híbridos quando infetados por PRSV e WMV apresentaram sintomas semelhantes àqueles observados para os vírus inoculados isoladamente. Os sintomas exibidos pelo híbrido Orange Flesh, quando inoculado com PRSV e WMV, mostraram-se mais severos, em comparação com os sintomas apresentados pelos híbridos Hy Mark e Gold Mine (Tabela 1). Além do mosaico clássico de cada vírus, isoladamente, as plantas apresentaram, bolhosidade, nervuras paralelas e deformação foliar leve (Figura 1G). Na combinação de ZYMV com PRSV, constatouse, mais uma vez, a presença do sintoma de enação em 'Hy Mark', sugerindo que este sintoma estaria relacionado ao sinergismo do ZYMV com qualquer um dos outros potyvírus (Figura 1H, Tabela 1). O híbrido Orange Flesh, também apresentou sintomas bastante severos, com presença de mosaico severo, deformação foliar e bolhosidade, quando infetados simultaneamente por ZYMV e por PRSV. A severidade dos sintomas, com a constante presença de enação em 'Hy Mark' (Figura 1H, seta), caracteriza o efeito sinérgico da interação ZYMV e PRSV em 'Hy Mark' (Tabela 1). A severidade dos sintomas próprios do ZYMV é enfatizada por vários pesquisadores (Lisa \& Lecoq, 1984; Huang et al., 1993, Oliveira et al., 2000), o que justifica a predominância dos seus sintomas na interação e o aparecimento de sintomas mais severos e diferentes dos encontrados em infecções simples do ZYMV (Tabela 1).

Os sintomas das variedades de melancia Crimson Sweet e Charleston Gray, inoculadas com o ZYMV, foram mais discretos do que os sintomas apresentados pelos híbridos de meloeiro (Tabela 1). O PRSV causou sintomas clássicos de mosaico, mosqueado e deformação foliar leve nas duas

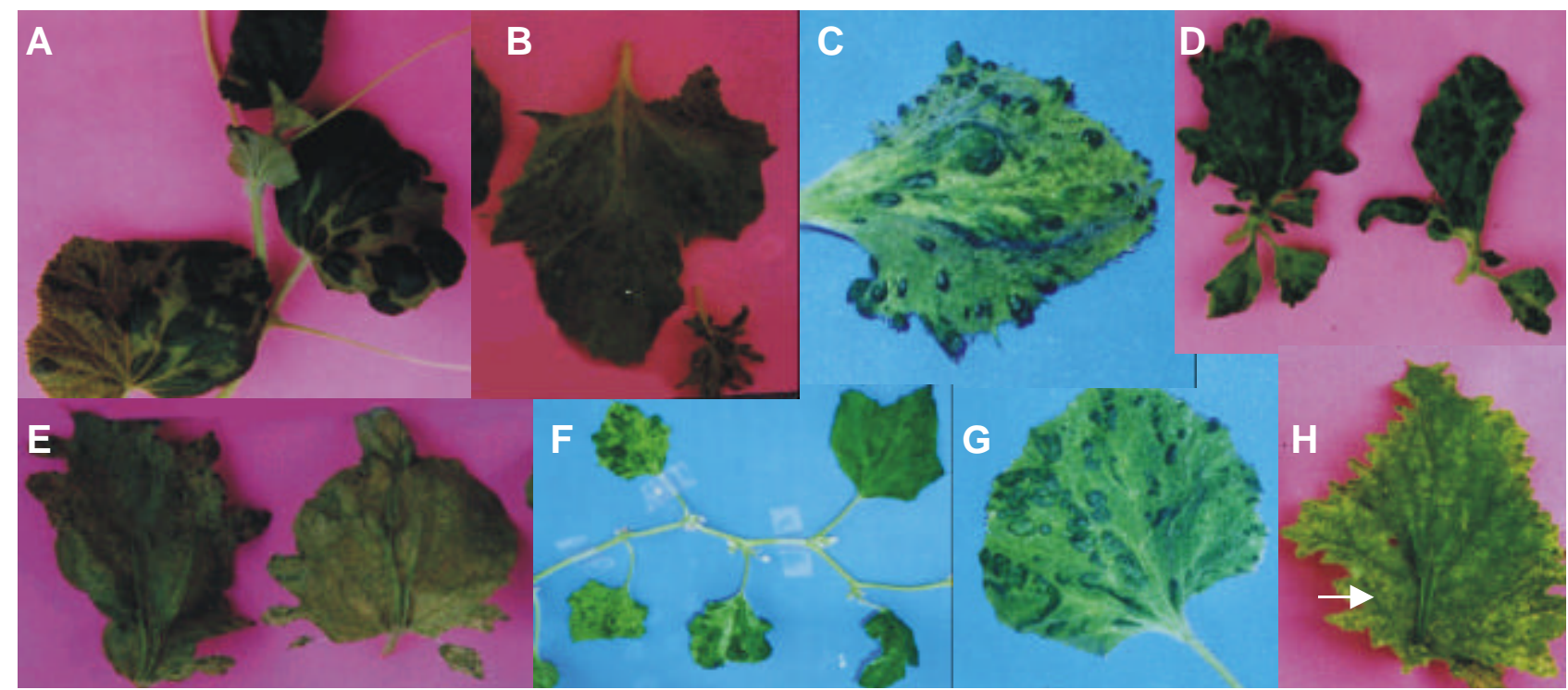

FIG. 1 - Sintomas de mosaico, deformação foliar e bolhosidade induzidos pelo Zucchini yellow mosaic virus (ZYMV) em híbridos de meloeiro (Cucumis melo): A) 'Hy Mark', B) 'Gold Mine' e C) 'Orange Flesh'; D, E e F - Sintomas de mosaico, deformação foliar, bolhosidade e enação induzidos pela combinação de ZYMV e Watermelon mosaic virus (WMV) em D) 'Hy Mark', E) 'Gold Mine' e F) 'Orange Flesh', e G) mosaico, bolhosidade, nervuras paralelas e deformação foliar leve induzidos pela combinação de Papaya ringspot virus (PRSV) e WMV em 'Orange Flesh'; H) mosaico, bolhosidade, deformação foliar leve e enação (seta) induzidos pela combinação de PRSV e ZYMV em 'Hy Mark'. 


\section{N.F. Ramos et al.}

TABELA 1 - Sintomas exibidos por abobrinha (Cucurbita pepo) 'Caserta', híbridos de meloeiro (Cucumis melo) e variedades de melancia (Citrullus lanatus) inoculados com Papaya ringspot virus (PRSV), Watermelon mosaic virus (WMV) e Zucchini yellow mosaic virus (ZYMV), isolados ou em combinação, em experimento de casa de vegetação

\begin{tabular}{|c|c|c|c|c|c|c|}
\hline \multirow{3}{*}{$\begin{array}{l}\text { Vírus/Combinação de } \\
\text { Vírus }\end{array}$} & \multicolumn{6}{|c|}{ SINTOMATOLOGIA* } \\
\hline & \multirow[b]{2}{*}{$\begin{array}{l}\text { Abobrinha } \\
\text { Caserta }\end{array}$} & \multicolumn{3}{|c|}{ Meloeiro } & \multicolumn{2}{|c|}{ Melancia } \\
\hline & & Hy Mark & Gold Mine & $\begin{array}{l}\text { Orange } \\
\text { Flesh }\end{array}$ & $\begin{array}{c}\text { Crimson } \\
\text { Sweet }\end{array}$ & $\begin{array}{c}\text { Charleston } \\
\text { Gray }\end{array}$ \\
\hline ZYMV & M, Df, Bl, Cs & $\mathrm{M}, \mathrm{Bl}, \mathrm{Df}$ & $\mathrm{M}, \mathrm{Bl}, \mathrm{Df}$ & $\mathrm{M}, \mathrm{Bl}, \mathrm{Df}$ & $\mathrm{M}, \mathrm{Bl}$ & $\mathrm{M}, \mathrm{Bl}$ \\
\hline PRSV & M, Df LEVE & M & M & M & M, Df LEVE & M, Df LEVE \\
\hline WMV & M & M & M & M & M & M \\
\hline ZYMV + WMV & M, Df, Bl, En, Ef & M, Df, Bl, En & M, Df, Bl, En & M, Df, Bl, En & M, Df, Ef, Sd & M, Df, Sd, Fp \\
\hline PRSV + WMV & $\mathrm{M}, \mathrm{Df}$ & M & M & $\mathrm{M}, \mathrm{Df}, \mathrm{Bl}, \mathrm{Np}$ & M, Df LEVE & M, Df LEVE \\
\hline ZYMV + PRSV & M, Df, Bl, Es & M, Bl, Df, En & $\mathrm{M}, \mathrm{Bl}, \mathrm{Df}$ & $\mathrm{M}, \mathrm{Bl}, \mathrm{Df}, \mathrm{Bf}$ & $\mathrm{M}, \mathrm{Df}, \mathrm{Bl}, \mathrm{Sd}$ & $\mathrm{M}, \mathrm{Df}, \mathrm{Sd}, \mathrm{Bl}, \mathrm{Cs}$ \\
\hline Plantas sadias & $\mathrm{S} / \mathrm{S}$ & $\mathrm{S} / \mathrm{S}$ & $\mathrm{S} / \mathrm{S}$ & $\mathrm{S} / \mathrm{S}$ & $\mathrm{S} / \mathrm{S}$ & $\mathrm{S} / \mathrm{S}$ \\
\hline
\end{tabular}

* Bf: bordas franzidas; Bl: bolhosidade; Es: esporão; Et: estreitamento foliar; Cs: cordão de sapato; Df: deformação foliar; Ef: enrolamento foliar; En: enação; Fp: florescimento precoce; M: mosaico; Np: nervuras paralelas; Sd: subdesenvolvimento; S/S: sem sintomas.

variedades de melancia (Tabela 1) e o WMV ocasionou um intenso mosaico em ambas as variedades (Tabela 1). Quando inoculadas com ZYMV e com WMV, as variedades de melancia apresentaram sintomas bastante severos, caracterizados por mosaico, com plantas subdesenvolvidas, deformação foliar, enrolamento foliar e florescimento precoce. Evidências de aumento de severidade em plantas inoculadas com dois potyvírus já foram relatadas por Lot et al. (1998) e Takaichi et al. (2001).

Os sintomas exibidos pelas variedades de melancia submetidas às inoculações de PRSV e de WMV foram semelhantes àqueles apresentados pelas plantas inoculadas com os vírus isoladamente, não havendo intensificação dos sintomas com a infecção dupla (Tabela 1). A ausência de sintomas severos com a combinação de PRSV e WMV tanto nos híbridos de meloeiro, como nas variedades de melancia, pode estar associada à baixa severidade dos sintomas nas infecções isoladas de cada vírus (Tabela 1), o que indica a ausência de efeito sinérgico entre os mesmos em melancia.

No entanto, quando as mesmas variedades de melancia foram inoculadas com ZYMV e com PRSV, constatou-se aumento de severidade de sintomas, tendo 'Charleston Gray' apresentado sintomas de subdesenvolvimento de planta e de folhas, mosaico, bolhosidade, deformação foliar e cordão de sapato, sintomas não verificados nas plantas inoculadas com os vírus isoladamente, mesmo no caso do ZYMV, que sozinho ocasionou sintomas severos nesta variedade (Tabela 1). Verificou-se, também, na infecção dupla de ZYMV e PRSV superbrotamento da ponta do ramo, conferindo à planta um aspecto de roseta. Na variedade Crimson Sweet, os sintomas apresentados pelas plantas com infecção dupla foram bem mais severos do que os apresentados pelo PRSV inoculado isoladamente e com maior intensidade do que os apresentados por ZYMV isoladamente (Tabela 1).

Em abobrinha 'Caserta' os três vírus induziram a formação de seus sintomas típicos, quando inoculados isoladamente (Figura 2, Tabela 1), sendo que o ZYMV ocasionou os sintomas mais severos, constituídos de mosaico,

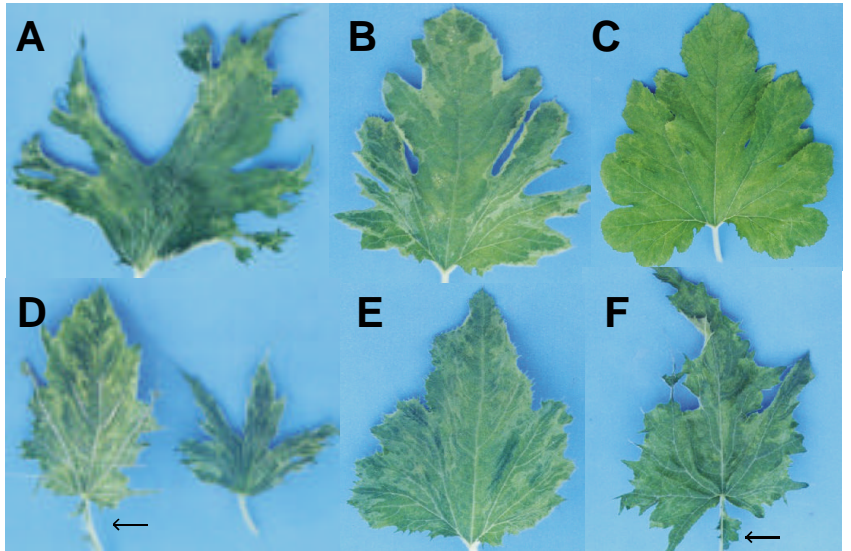

FIG. 2 - Sintomas em abobrinha (Cucurbita pepo) 'Caserta' induzidos pela combinação de potyvirus: A) mosaico, deformação foliar e bolhosidade induzidos por Zucchini yellow mosaic virus (ZYMV), B) mosaico e deformação foliar induzidos por Papaya ringspot virus (PRSV); C) mosaico e deformação foliar induzidos por Watermelon mosaic virus (WMV); D) mosaico, bolhosidade, deformação foliar, enrugamento foliar e crescimento do limbo foliar no pecíolo (esporão, seta) da folha induzidos pela combinação de ZYMV e WMV; E) mosaico e deformação foliar induzidos pela combinação de PRSV e WMV e F) mosaico, deformação foliar, bolhosidade e crescimento do limbo foliar no pecíolo da folha (esporão) induzidos pela combinação de PRSV e ZYMV.

deformação foliar e bolhosidade (Figura 2A). O PRSV e o WMV ocasionaram sintomas mais leves, mas sempre com mosaico e deformação foliar (Figura 2B, C). Quando inoculada com ZYMV e WMV, abobrinha 'Caserta' exibiu sintomas mais severos que os sintomas exibidos pelos mesmos vírus inoculados separadamente (Figura 2D, Tabela 1). Na infecção dupla de ZYMV e WMV, os principais sintomas foram mosaico, bolhosidade severa, forte deformação foliar, enrugamento foliar e crescimento do limbo foliar no pecíolo da folha, com aparência de esporão (Figura 2D, seta), não constatado em plantas com infecção simples de potyvirus. Quando 
inoculada com PRSV e com WMV, a abobrinha 'Caserta' apresentou uma mistura de sintomas dos dois vírus, resultando em mosaico e deformação foliar (Figura 2E, Tabela 1).

As plantas de abobrinha 'Caserta' inoculadas com ZYMV e com PRSV apresentaram sintomas extremamente severos, com crescimento do limbo foliar no pecíolo da folha (esporão), mosaico, deformação foliar e bolhosidade (Figura 2F, Tabela 1).

A presença de cada vírus foi confirmada por ELISA indireto em todos os casos de infecção simples e dupla, incluindo aqueles em que a inoculação de dois vírus não resultou em aumento de severidade de sintomas.

As reações sintomatológicas diferenciadas, apresentadas pelos híbridos de meloeiro, pelas cultivares de melancia e abobrinha 'Caserta', inoculados com os três potyvírus, revelaram variabilidade genética e efeitos interativos diferenciados entre os vírus (Tabela 1).

\section{REFERÊNCIAS BIBLIOGRÁFICAS}

ALMEIDA, A.M.R. Detecção e quantificação de vírus pelo teste ELISA. In: Almeida, A.M.R. \& Lima, J.A.A. (Eds.) Princípios e técnicas aplicados em fitovirologia. Fortaleza. Fitopatologia Brasileira. 2001. pp. 63-94.

BHARGAVA, B. Effect of watermelon mosaic virus on the yield of Cucurbita pepo. Acta Phytopathologica Academiae Scientiarum Hungaricae 12:165-168. 1977.

CALVERT, L.A., \& GHABRIAL, S.A. Enhancement by soybean mosaic virus of bean pod mottle virus titer in double infected soybean. Phytopathology 73:992-997. 1983.

GONÇALVES, F.C., MENEZES, J.B. \& ALVES, R.E. Vida útil pós-colheita de melão 'piel de sapo' armazenado em condição ambiente. Horticultura Brasileira 14:49-52. 1996.

HUANG, C.H., LIANG, S.C., DENG, T.C. \& HSEU, S.H. Comparison of diagnostic host and serological tests for four cucurbit potyviruses. Plant Pathology Bulletin 2:169-176. 1993.

IBGE. Anuário Estatístico do Brasil/SIDRA. Rio de Janeiro. 1997.

LISA, V. \& LECOQ, H. Zucchini yellow mosaic virus $\mathrm{n}^{\circ} 282$. Description of plant viruses. CMI/AAB, Kew England. 1984.

LOT, H., CHOVELON, V., SOUCHE, S. \& DELECOLLE, B. Effects of onion yellow dwarf and leek yellow strip viruses on symtomatology and yield loss of three French garlic cultivars. Plant Disease 82:13811385. 1998

OLIVEIRA, V.B., LIMA, J.A.A., VALE, C.C. \& PAIVA, W.O. Caracterização biológica e sorológica de isolados de potyvirus obtidos de cucurbitáceas no Nordeste brasileiro. Fitopatologia Brasileira 25:628-636. 2000.

PERRING, T.M., FARRAR, C.A., MAYBERRY, K. \& BLUA, M.J. Research reveals pattern of cucurbit virus spread. California Agriculture 46:35-40. 1992.

POOLPOL, P. \& INOUYE, T. Enhancement of cucumber mosaic virus multiplication by zucchini yellow mosaic virus in double infected cucumber plants. Annals of Phytopathological Society of Japan 52:22-30. 1986.

PROVVIDENTI, R., GONSALVES, D. \& HUMAYDAN, H.J. Occurrence of zucchini yellow mosaic virus in cucurbits from Connecticut, New York, Flórida, and California. Plant Disease 68:443-446. 1984.

TAKAICHI, M., NAGAKUBO, T. \& OEDA, K. Mixed virus infections of garlic determined by a multivalent polyclonal antiserum and virus effects on disease symptoms. Plant Disease 85:71-75. 2001. 